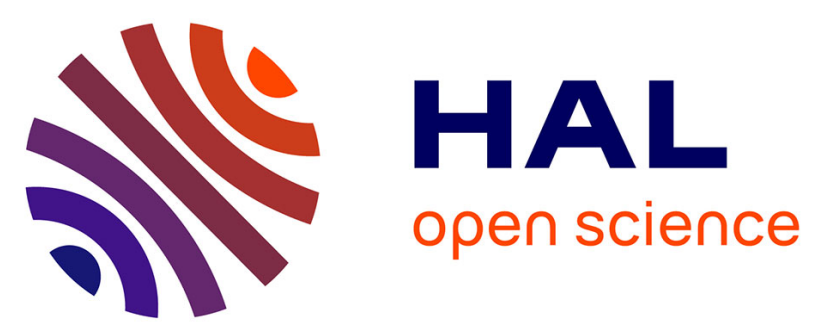

\title{
A new device for measurement of permeability evolution under pressure loading: application to CFRP pipes
}

Hortense Laeuffer, Jamal Arbaoui, Christophe Bois, Florian Lavelle, Nicolas Perry, Jean Christophe Wahl

\section{- To cite this version:}

Hortense Laeuffer, Jamal Arbaoui, Christophe Bois, Florian Lavelle, Nicolas Perry, et al.. A new device for measurement of permeability evolution under pressure loading: application to CFRP pipes. Measurement - Journal of the International Measurement Confederation (IMEKO), 2017, 98, pp.68-76. 10.1016/j.measurement.2016.11.023 . hal-01500117

\section{HAL Id: hal-01500117 https://hal.science/hal-01500117}

Submitted on 2 Apr 2017

HAL is a multi-disciplinary open access archive for the deposit and dissemination of scientific research documents, whether they are published or not. The documents may come from teaching and research institutions in France or abroad, or from public or private research centers.
L'archive ouverte pluridisciplinaire HAL, est destinée au dépôt et à la diffusion de documents scientifiques de niveau recherche, publiés ou non, émanant des établissements d'enseignement et de recherche français ou étrangers, des laboratoires publics ou privés. 


\title{
A new device to measure permeability evolution under pressure loading: Application to CFRP pipes
}

\author{
Hortense Laeuffer $^{\mathrm{a}, \mathrm{b}, *, 1}$, Jamal Arbaoui ${ }^{\mathrm{a}, \mathrm{b}}$, Christophe Bois ${ }^{\mathrm{b}, *}$, Florian Lavelle ${ }^{\mathrm{a}}$, Nicolas Perry ${ }^{\mathrm{c}}$, \\ Jean-Christophe Wahl ${ }^{\mathrm{b}}$ \\ ${ }^{a}$ CNES, Launcher Directorate, F-75012 Paris, France \\ ${ }^{\mathrm{b}}$ Univ. Bordeaux, I2M, UMR 5295, F-33400 Talence, France \\ ${ }^{\mathrm{c}}$ Arts et Metiers ParisTech, I2M, UMR 5295, F-33400 Talence, France
}

Keywords:

Gas permeability

Pressure vessel

Leak

Composite laminate

Damage

Matrix cracking

\begin{abstract}
A B S T R A C T
This paper presents an experimental setup to measure permeability evolution induced by mechanical loading. The experiment consists in pressurising a pipe-specimen. Internal pressure is used to load and to measure permeability. The external face of the pipe is accessible, so that leak paths can be localised and quantified. In order to avoid premature cracking of the specimen due to the device, sealing components were designed using Finite Element Analysis with respect to the stiffness of pipes to be tested. Although the current design is used here to test carbon composite pipes, it can be easily adapted to other materials. The design was validated by measuring permeability on an impermeable pipe. The experimental setup and method were applied to a composite filament-wound pipe. Results give substantial quantitative information on the relationship between the number of leak paths and the increase in material permeability.
\end{abstract}

\section{Introduction}

Because they have a good ratio between low density and good mechanical properties, Carbon Fibre Reinforced Plastics (CFRP) are used more and more as a means of reducing the weight of satellite launch vehicles. These materials are already used for gas pressure vessels, but always combined with a metallic or polymer gas-tight liner. Such liners are heavy and expensive to manufacture but they can be removed, provided the CFRP wall fulfils the gas barrier function $[1,2]$. For long-term or high-pressure storage the leakage rate requirement is too stringent for this application to be possible. However, in the case of short-term storage, e.g. propellant vessels of launch vehicles, the intrinsic permeability of a pristine CFRP laminate meets these requirements.

As CFRP are strongly heterogeneous materials, damage growth may occur at low levels of thermo-mechanical loading. At the micro-scale level, damage growth results in decohesion between fibre and matrix, as well as micro-cracking of the matrix. This micro-damage coalesces into transverse cracks at the ply scale

* Corresponding authors at: I2M - IUT Univ. Bordeaux, 15 rue Naudet - CS 10207 , 33175 GRADIGNAN Cedex, France.

E-mail addresses: hortense.laeuffer@u-bordeaux.fr (H. Laeuffer), christophe. bois@u-bordeaux.fr (C. Bois).

1 Principal corresponding author.
[3], with micro-delamination at crack tips [4]. Delamination results in cracks in adjacent plies connecting together (Fig. 1). When all plies are damaged, this crack network may go through the entire thickness of the composite wall, and lead to gas leakage [5]. Damage growth and leak formation are therefore core issues for linerless CFRP vessels.

Models have been introduced to predict the damage state, i.e. crack density and delamination length, from the loading history and the material properties [4,6-12]. Damage state and current loading can then be used as input for crack opening displacement prediction $[10,11,13]$, and also for permeability prediction [11-17]. Yet the prediction of crack connections managed by crack length and distribution remains a core issue and still requires experimental data on the link between load, number of leak paths and permeability.

Conventional permeability devices use a plate-specimen $[13,18-23]$ surrounded by two gas chambers. Crack growth and permeability measurement are often carried out separately $[18,19,21]$. The main problem is that the specimen is unloaded for permeability measurement, so that in most cases cracks are closed; only in some cases do very large cracks remain open (e.g. cracks in thick plies or cracks in materials with a high level of thermal residual stresses). In some studies decoupled yet simultaneous loading of the specimen and measurement of the permeability 


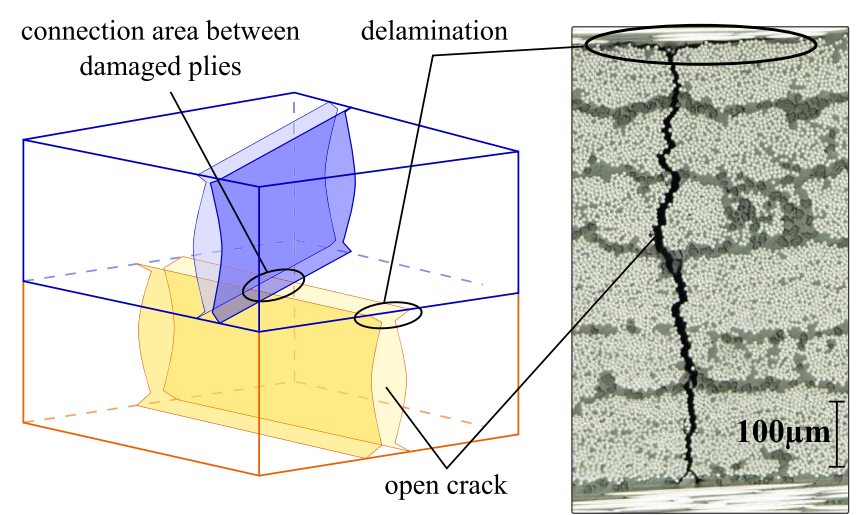

Fig. 1. Transverse crack and delamination: left, schematic crack network in two damaged plies, right, micrograph of a damaged ply.

have been carried out $[13,22,24]$. The plate-specimen principle appears not to be adapted to transverse cracking-induced leakage since cracks propagate up to sample edges, generating leaks outside the confined area [13,19-22]. Taking measurements on pipespecimens has been suggested as a solution to simultaneously loading the specimen and assessing its permeability $[2,25]$. The device proposed in both references is a closed pipe, embedded in a vacuum or cryogenic chamber. In [25] cryogenic conditions and tensile loading are applied to the specimen. The use of a pipespecimen solves the surface sealing problem, but is questionable because of the effect of the apparatus itself on the pressurised pipe. Moreover, because of the chamber, leak paths cannot be observed.

This paper offers an experimental setup and method to assess load-induced permeability. Samples are pipes subjected to internal pressure without end-effect. Internal pressure is used for both mechanical loading and permeability measurement. The device is intended for characterisation purposes by testing various lay-ups, the aim being to understand how leaks are generated and identify prediction models. The device also enables leak path quantification and localisation. In order to control the loading, and thereby the damage state, particular attention is paid to the design of the sealing components of the device. The method used to access the intrinsic permeability of the material is detailed and the device capability is evaluated using a reference (i.e. impermeable) pipe. Results obtained with a composite pipe subjected to crackinduced leakage are then presented and discussed.

\section{Permeability: definition and measurement}

\subsection{Notion of permeability}

Permeability $k$ is the material constant that characterises the ability of a porous medium to be crossed through by a fluid when subjected to a pressure gradient. For a steady and uni-axial flow, as described in Fig. 2, permeability can be computed from Darcy's law as the proportionality link between the volume flow rate $Q$, the pressure gradient through the thickness of the specimen $d p / d x$, and the dynamic viscosity $\mu$ of the fluid:

$\frac{Q}{S}=\frac{k}{\mu} \frac{d p}{d x}$

for a Newtonian fluid with $Q$ the leakage rate $\left(\mathrm{m}^{3} \mathrm{~s}^{-1}\right), S$ the measurement area $\left(\mathrm{m}^{2}\right), k$ the intrinsic permeability of the material $\left(\mathrm{m}^{2}\right), \mu$ the dynamic viscosity of the fluid (Pa s), and $d p / d x$ the pressure gradient through the thickness of the specimen $\left(\mathrm{Pa} \mathrm{m}^{-1}\right)$. The following assumptions are made: ideal gas, uni-axial flow in

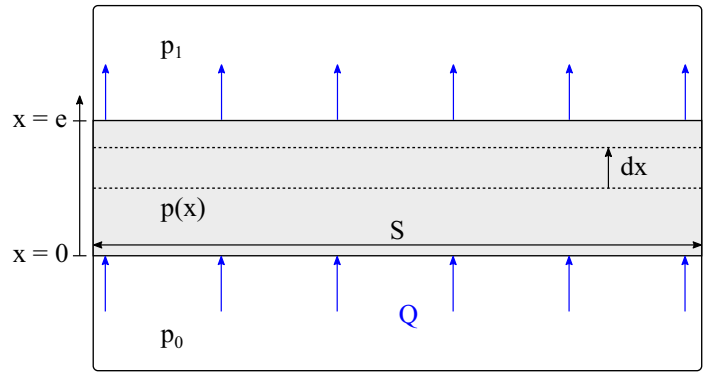

Fig. 2. Diagram of stationary permeability measurement.

direction $\underline{x}$, steady and isothermal flow, negligible effect of inertia, negligible deformation of the porous medium.

Low permeability molecular flow due to diffusion, namely the slipping of the gas molecule through small pores, makes Eq. (1) inaccurate. Indeed, parameter $k$ appears to be decreasing up to an asymptote when pressure increases. This phenomenon, called the Klinkenberg effect [26], can be modelled by redefining $k$ as the apparent permeability, measured by the Darcy experiment, and $k_{m}$ as the intrinsic permeability of the material:

$k=k_{m}\left(1+b / p_{m}\right)$

$b(\mathrm{~Pa})$ is the Klinkenberg coefficient, which particularly depends on the fluid used, and $p_{m}=\left(p_{0}+p_{1}\right) / 2$ the mean of upstream and downstream pressures $p_{0}$ and $p_{1}$. Coefficient $b$ and intrinsic permeability $k_{m}$ have to be assessed by several measurements of $k$ for various pressure levels.

\subsection{Measurement method}

A generic permeability determination method consists in keeping two of the three quantities constant, the upstream and downstream pressures and the leakage rate, while measuring variations in one of them. With stationary methods such as the Darcy experiment, the measured quantity is the volume flow rate, and $k$ is computed from Eq. (1). For weakly permeable media, i.e. with $k<10^{-15} \mathrm{~m}^{2}$, the flow rate is very small and practically impossible to measure, and therefore one usual measurand is pressure loss or gain. Thus, unsteady $[27,28]$ and quasi-steady [23] methods have been developed to measure the permeability of such materials. For an overview of leak rate measurement methods, the reader may refer to [29].

The measurement method used herein is similar to the quasisteady method of Jannot and Lasseux [23], except that pressure variations are measured on upstream pressure $p_{0}(t)$ instead of downstream pressure, and downstream side is subjected to atmospheric pressure, which yields the boundary conditions expressed below. From mass conservation, Darcy's law with the Klinkenberg effect (Eqs. (1) and (2)), ideal gas law, and considering that material pores are already filled with gas, the quasi-diffusion equation is written:

$\frac{\partial^{2}(p(x, t)+b)^{2}}{\partial x^{2}}=0$

with a constant boundary condition at downstream side:

$p(x=e, t)=p_{1}$

where $e$ denotes thickness $(\mathrm{m})$, and a quasi-steady boundary condition at upstream side:

$p(x=0, t)=p_{0}(t)$

gives: 
$\frac{d p_{0}(t)}{d t}=\frac{1}{2} \frac{S}{\mu V_{0}} k_{m} \frac{\partial(p(x, t)+b)^{2}}{\partial x}$ at $x=0$

where $V_{0}$ denotes upstream gas volume $\left(\mathrm{m}^{3}\right)$.

Provided the variation in $p_{0}(t)$ for $t \in\left[t_{A} ; t_{B}\right]$ is small compared to the initial pressure $p_{0}\left(t_{A}\right), d p_{0}(t) / d t$ can therefore be considered constant and equal to the slope $\alpha$ of the linear regression of $p_{0}(t)$ over $\left[t_{A} ; t_{B}\right]$. Then, after integration, resolution of Eq. (3) leads to the following expressions of $k_{m}$ :

$k_{m}=\frac{2 \mu e V_{0}}{S} \frac{\alpha}{\left(\frac{p_{0}\left(t_{A}\right)+p_{1}}{2}+b\right)\left(p_{0}\left(t_{A}\right)-p_{1}\right)}$

If the Klinkenberg effect is negligible, permeability $k$ is given by:

$k=\frac{2 \mu e V_{0}}{S} \frac{\alpha}{p_{0}\left(t_{A}\right)^{2}-p_{1}^{2}}$

In practice, $k_{m}$ is determined using a high value for $p_{0}$ compared to the expected value for $b$, and $b$ is then determined using other results obtained using a lower value of $p_{0}$. We can also directly find the best fitting value for $k_{m}$ and $b$ on all experimental results, provided $k_{m}$ and $b$ remain constant.

\section{Design of an experimental device for permeability measurements}

\subsection{Description of the setup and design key points}

The setup consists of a closed pipe with a gas inlet and a pressure sensor (Fig. 3). The pipe specimen can be pressurised and the pressure loss measured over time, from which the permeability of the material is computed according to Eq. (8) or (7). For safety reasons, the internal volume is reduced by a solid PVC cylinder to limit the energy stored in the compressed gas.

The internal pressure is set with a compressed gas cylinder. Gas can be either nitrogen or helium. The pipe is instrumented with a pressure sensor. Strain gauges and a temperature sensor could be added. A relative pressure sensor is used, which gives the pressure difference $p_{0}-p_{1}$ directly. Between the pipe and the end plates, sealing rings with pipe seals prevent the device from leaking.

The measured permeability is that of the whole setup, device and specimen combined. The main difficulty is to ensure that leaks from the device remain smaller than the precision required for the experiment. Another difficulty is to control the load induced by the sealing device on the pipe. For these reasons, special attention was given to the design of the sealing rings and position of the seals.

When the pipe is subjected to internal pressure, it undergoes radial deformations leading to a significant increase in the pipe radius. Thus, the simplest way to keep the seal in contact with the pipe at all times is to place it on the outside of the pipe and maintain it with a ring (Fig. 4). A wedge bushing is used to control the position of the pipe in relation to the seal. Moreover, to adjust the external diameter of different composite pipes to the seal, a polymer bushing is bonded onto the pipe. This bushing also ensures a good surface roughness for sealing. The sealing between the sealing ring and the thrust plate is managed by using a second seal.

The next section describes how the ring supporting the two seals was designed with the help of Finite Element (FE) Analysis.

\subsection{Design of sealing ring using FE analysis}

The two main functional requirements for the sealing ring are, (i) to keep the seal in its groove, and (ii) to control the load induced by the sealing device on the pipe. Requirement (i) consists in making sure that the gap between the sealing ring and the contact

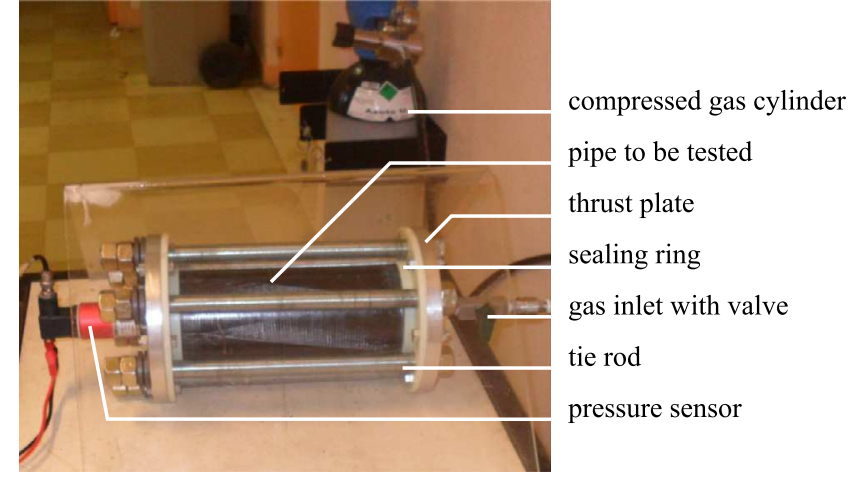

Fig. 3. Experimental device for measuring permeability of a pipe under pressure.
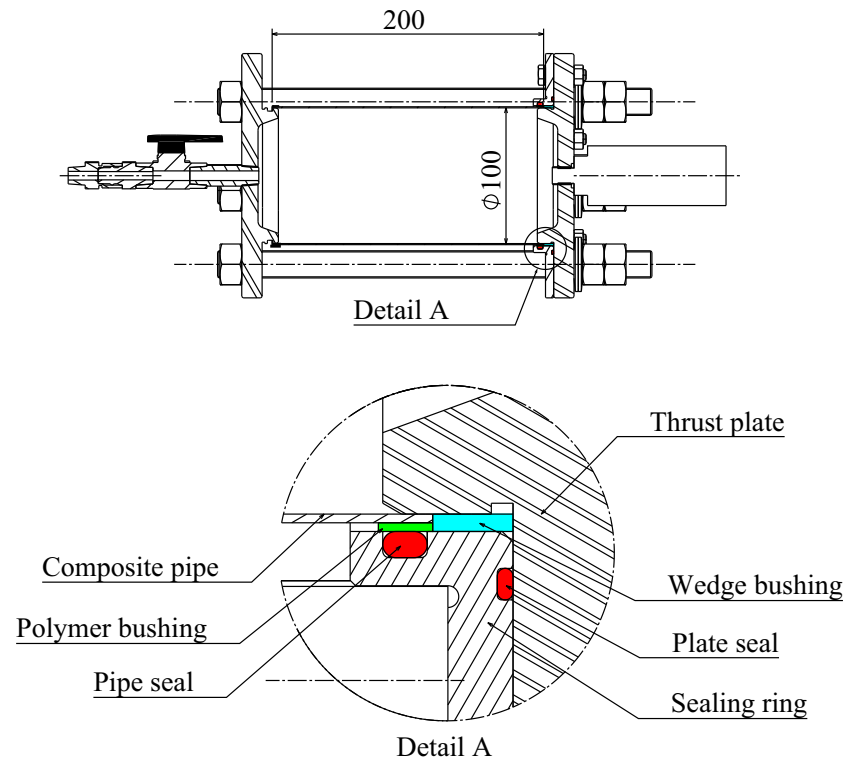

Fig. 4. Sealing system.

surface of the seal is small enough to avoid extrusion of the seal. The seal supplier gives the maximum allowable gap according to fluid pressure and cross-section seal diameter. Requirement (ii) consists in verifying that no premature damage or fracture occurs in the sealing area and that the length where stress or strain field is affected by the sealing device is small compared to the pipe length.

The two requirements can appear contradictory since requirement (ii) leads to a reduction in the interaction load between the pipe and the ring, while requirement (i) needs to limit the distance between the two parts. One solution consists in adjusting the sealing ring stiffness to find the best compromise between the two functional requirements. Design parameters are the material and shape of the ring and the diameter of the seal. The main difficulty lies in the fact that this compromise has to work for a range of pipe stiffnesses. The design was thus evaluated with two composite pipes, one with a $[+45 /-45]_{s}$ lay-up, resulting in a flexible pipe (radial displacement equal to $0.2 \mathrm{~mm} / \mathrm{MPa}$ ), and another with a $[90 /-45 /+45 / 90]$ lay-up, resulting in a stiff pipe (radial displacement equal to $0.047 \mathrm{~mm} / \mathrm{MPa}$ ).

A soft material (polymer PA66) was selected. The ring is made of a flange, in order to fix it on the thrust plate, and a cylindrical part where the seal groove is machined. Another seal groove is added to the flange plane to create the seal between the thrust plate and the ring. The ring stiffness can then be adjusted by 
adjusting the length of the cylindrical part. However, increasing this length also increases the surface subjected to the internal pressure, which generates a deformation of the ring, whatever the pipe stiffness. An axial groove is therefore added in order to reduce the ring stiffness without increasing the surface subjected to internal pressure.

Stress and displacement were analysed using axisymmetric FE modelling. The thrust plate is assumed infinitely rigid and seals are assumed infinitely soft and are therefore not modelled. Pressure is applied on the inner surfaces delimited by the seals, as shown in Fig. 5(a). The bolted joint between the ring and the thrust plate is modelled by a clamped boundary condition. A friction-free contact condition with an initial clearance of $0.05 \mathrm{~mm}$ is defined between the sealing ring and the polymer bushing. Material constants used for the FE modelling are summarised in Table 1.

Fig. 5(b) and (c) show the deformed shape and the displacement field in radial direction for the flexible and the stiff pipe for an internal pressure of $2 \mathrm{MPa}$. As expected, for the flexible pipe the gap between the sealing ring and the wedge bushing remains at zero, while that gap reaches $0.085 \mathrm{~mm}$ for the stiff pipe. This is close to the maximum allowable gap in terms of seal extrusion ( 0.09 for a $3 \mathrm{~mm}$ cross-section seal diameter). The gap between the ring and the thrust plate where the second seal is placed has also to be checked, especially for the flexible pipe. This gap is close to $0.05 \mathrm{~mm}$, which is slightly less than the maximum allowable gap ( $0.08 \mathrm{~mm}$ for a $2 \mathrm{~mm}$ cross-section seal diameter).

Concerning the effect of the load induced by the sealing device on the pipe, strain components along the centreline of the pipe layup are plotted in Fig. 6 for the flexible pipe and internal pressure of $2 \mathrm{MPa}$. 1 denotes the fibre direction and 2 the in-plane direction. To highlight the influence of sealing ring stiffness, the curves obtained with a ring made of aluminium alloy are also plotted. Increasing ring stiffness leads to an increase in the length where strain field is affected by the sealing device, also in overtaking value and in out-of-plane shear strain $\varepsilon_{r x}$. An aluminium ring would thus produce inter-laminar cracking (delamination) and premature failure or leakage.

We can show that for a PA66 ring, in-plane strains decrease toward the end of the pipe, preventing any transverse cracking in the sealing area and consequently causes errors in permeability measurement. The length $L_{s}$ where strain field is affected by the sealing device is evaluated using a $5 \%$ cut-off on the value of shear in-plane strain (which produces transverse cracking for [+45/-45] lay-up), as shown in Fig. 6(a). $L_{s}$ increases from $11 \mathrm{~mm}$ to $15 \mathrm{~mm}$

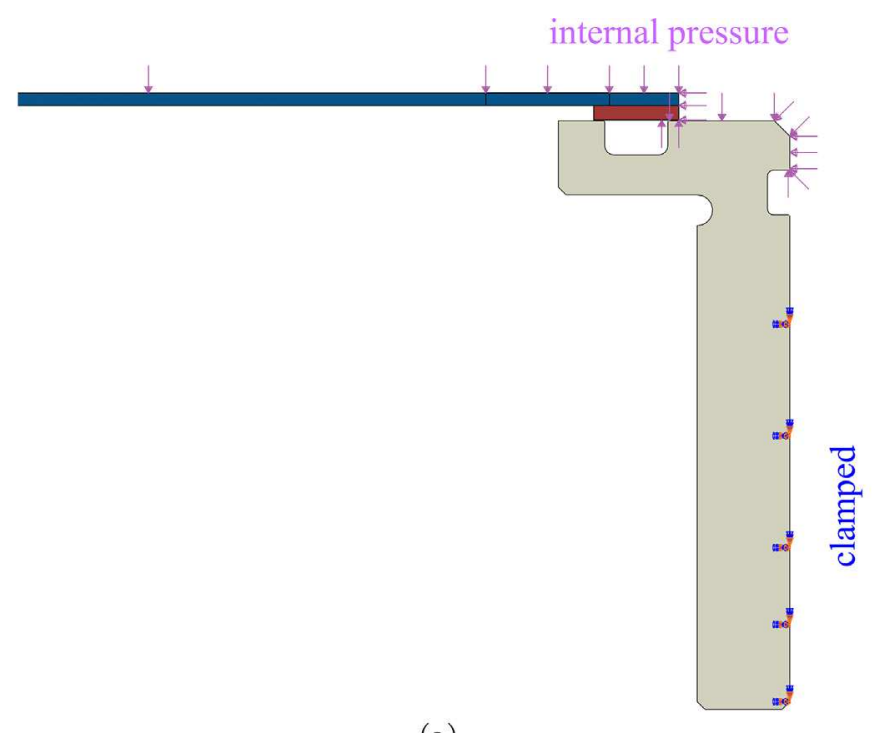

(a)
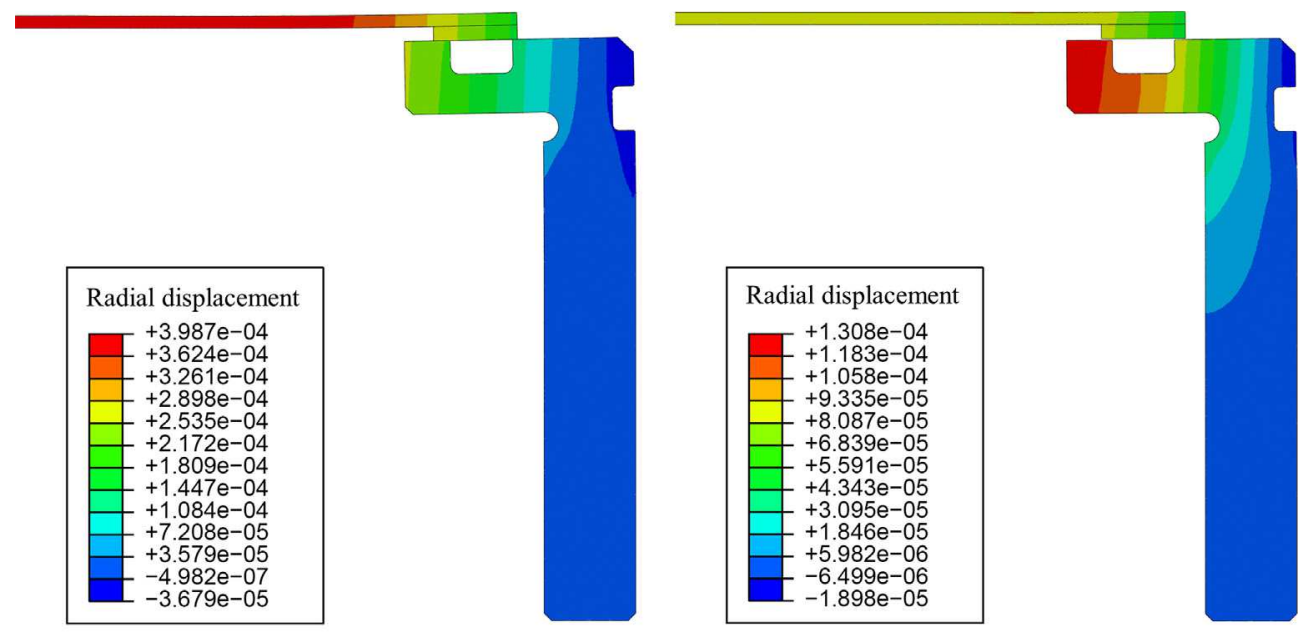

(b)

(c)

Fig. 5. FE analysis of the sealing system. (a) Boundary conditions, (b) radial displacement for the flexible pipe (m), (c) radial displacement for the stiff pipe (m). 
Table 1

Mechanical constants used for the FE modelling.

\begin{tabular}{|c|c|c|c|c|c|c|c|c|c|c|}
\hline \multirow{2}{*}{$\frac{\text { Part }}{\text { Wedge bushing }}$} & \multirow{2}{*}{$\begin{array}{l}\text { Material } \\
\text { PVC }\end{array}$} & \multicolumn{9}{|c|}{ Mechanical constant } \\
\hline & & \multicolumn{3}{|l|}{$\begin{array}{l}E \\
2.45\end{array}$} & \multicolumn{6}{|l|}{$\begin{array}{l}v \\
0.3\end{array}$} \\
\hline Sealing ring & PA66 & \multicolumn{3}{|l|}{$\begin{array}{l}E \\
1.83\end{array}$} & \multicolumn{6}{|l|}{$\begin{array}{l}v \\
0.3\end{array}$} \\
\hline Sealing ring and reference pipe & Aluminium alloy & \multicolumn{3}{|l|}{$\begin{array}{l}E \\
70\end{array}$} & \multicolumn{6}{|l|}{$\begin{array}{l}v \\
0.3\end{array}$} \\
\hline \multirow[t]{3}{*}{ CFRP pipes homogenised using laminate theory } & {$[+45 /-45 /-45 /+45]$} & $\begin{array}{l}E_{t t} \\
16.58\end{array}$ & $\begin{array}{l}E_{x x} \\
16.58\end{array}$ & $\begin{array}{l}E_{r r} \\
8.5\end{array}$ & $\begin{array}{l}v_{x r} \\
0.1\end{array}$ & $\begin{array}{l}v_{r t} \\
0.1\end{array}$ & $\begin{array}{l}v_{x t} \\
0.763\end{array}$ & $\begin{array}{l}G_{x r} \\
2.47\end{array}$ & $\begin{array}{l}G_{r t} \\
2.47\end{array}$ & $\begin{array}{l}G_{x t} \\
32.21\end{array}$ \\
\hline & {$[90 /-45 /+45 / 90]$} & $\begin{array}{l}E_{t t} \\
70.84\end{array}$ & $\begin{array}{l}E_{x x} \\
17.46\end{array}$ & $\begin{array}{l}E_{r r} \\
8.5\end{array}$ & $\begin{array}{l}v_{x r} \\
0.3\end{array}$ & $\begin{array}{l}v_{r t} \\
0.1\end{array}$ & $\begin{array}{l}v_{x t} \\
0.149\end{array}$ & $\begin{array}{l}G_{x r} \\
2.43\end{array}$ & $\begin{array}{l}G_{r t} \\
3.16\end{array}$ & $\begin{array}{l}G_{x t} \\
15.13\end{array}$ \\
\hline & Unit & $\mathrm{GPa}$ & $\mathrm{GPa}$ & GPa & - & - & - & $\mathrm{GPa}$ & $\mathrm{GPa}$ & GPa \\
\hline
\end{tabular}

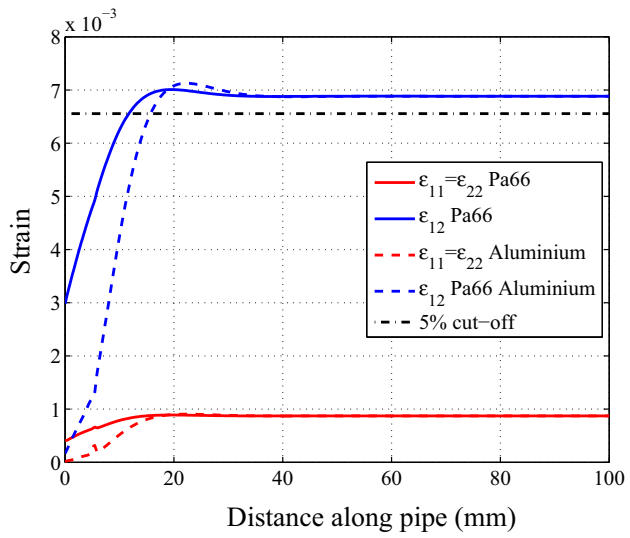

(a)

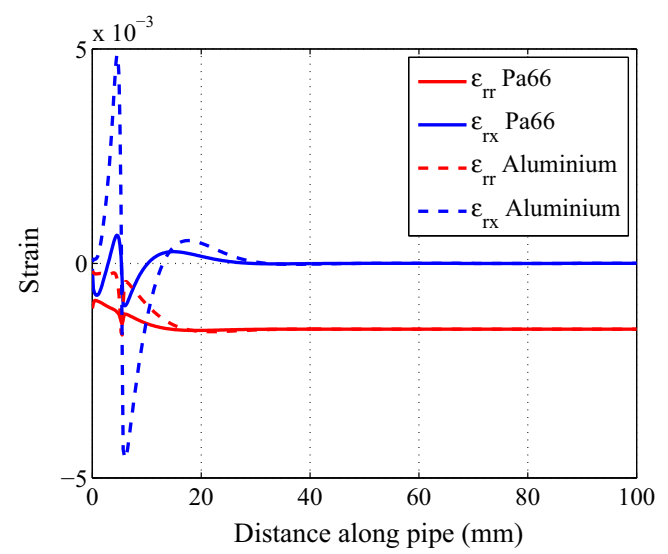

(b)

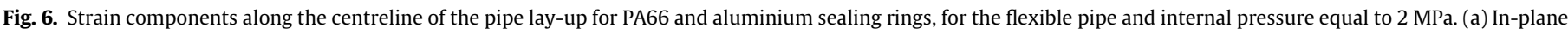
strains, (b) out-of-plane strains.

when the ring material is changed from PA66 to aluminium alloy. This analysis is useful for choosing the pipe length. A length of $200 \mathrm{~mm}$ was selected for testing the pipes, which ensures that the influence area of the device is quite small.

We can conclude that the present device is adapted to pipes with a radial displacement ranging from approximately $0.04 \mathrm{~mm} /$ $\mathrm{MPa}$ to $0.2 \mathrm{~mm} / \mathrm{MPa}$ up to a pressure of $2 \mathrm{MPa}$. Extending the performances of the device will mean designing a specific sealing ring for each tested pipe. Nevertheless, higher mechanical loading can be performed using water pressurisation and permeability properties evaluated afterwards with lower pressures.

\section{Data acquisition and processing methods}

\subsection{Measurement protocol}

Acquisition is carried out as follows. The internal pressure of the pipe is set with compressed gas. The valve of the device is then closed and measurement of the internal pressure is launched. While the pressure evolution is being measured, leak paths can be counted and localised over the external area of the pipe using leak detector spray. At the end of the measurement step, which has to be long enough to detect a pressure decrease in the pipe, the measurement data are processed in order to extract the pressure loss over time and the average pressure.

After each measurement step, the device can be set to a lower pressure, in order to examine the effect of crack closure on permeability, or to a higher pressure, in order to allow damage growth and creation of new leakage paths.

\subsection{Data processing}

The experimental data are relative pressure $p_{0}-p_{1}$ over time. The pressure response is segmented into parts of a pressure loss of at most $5 \%$ of the initial pressure of the considered segment $p_{0}\left(t_{A}\right)$. The pressure loss $p_{0}\left(t_{B}\right)-p_{0}\left(t_{A}\right)$ over each segment is measured by linear regression between $t_{A}$ and $t_{B}$, and associated to $p_{0}\left(t_{A}\right)$. This is done to ensure that the quasi-steady assumption is verified. As shown in Fig. 7 , a few points, fewer than $0.1 \%$, are very far from the mean value of the pressure at $\pm 0.2 \mathrm{MPa}$. However, standard deviation of the signal is similar to the nominal uncertainty of the sensor. Since the measurement distribution appears to be symmetrical (see Fig. 7(b)), a Gaussian filter is applied to reduce this noise. Acquisition frequency and length of the Gaussian filter are adjusted according to the permeability level. As shown in Fig. 8(a), the filtered pressure is useful to highlight non-expected phenomena and improve definition of segments. The filtering process has no influence on linear regression. The definition of segments and linear regressions are illustrated in Fig. 8(b).

Next, Eq. (8) is applied for each segment to obtain the permeability $k$ of the material (Table 2 ). It is worth noting that with this processing we can obtain several permeability values for different pressures with one initial applied pressure.

\subsection{Permeability of the device itself and validation of the design}

In order to evaluate the permeability of the device itself and validate the permeability measurement, a test was performed on a $1.8 \mathrm{~mm}$ thick, $200 \mathrm{~mm}$ long aluminium pipe which is not subjected 


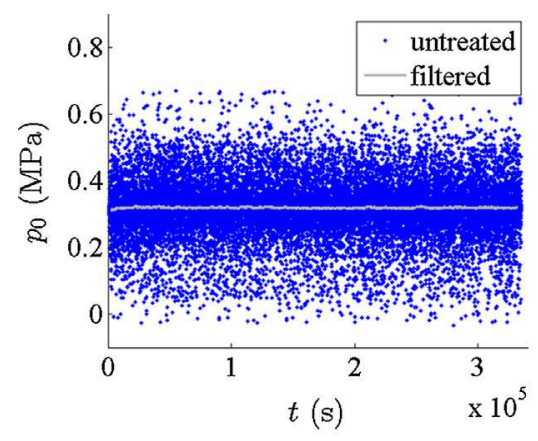

(a)

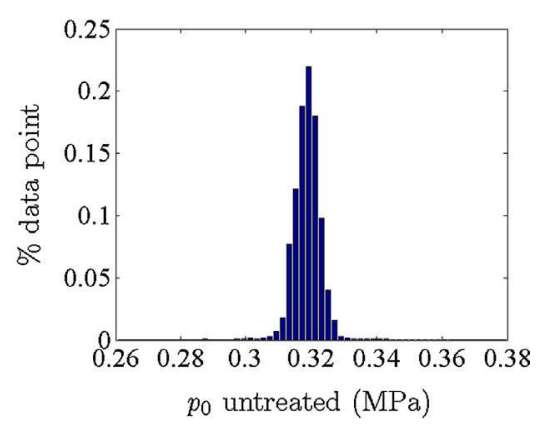

(b)

Fig. 7. (a) Pressure measurement over time, and (b) noise distribution.

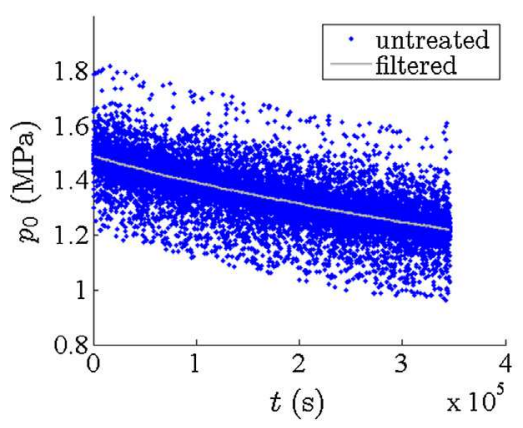

(a)

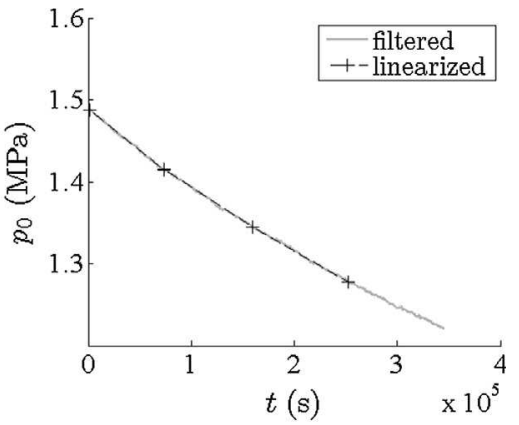

(b)

Fig. 8. (a) Untreated and filtered pressure, (b) linear approximation of the filtered pressure.

Table 2

Permeability results from Fig. 8.

\begin{tabular}{llll}
$p_{0}\left(t_{a}\right)(\mathrm{MPa})$ & 1.488 & 1.415 & 1.345 \\
$k\left(\mathrm{~m}^{2}\right)$ & $11.1 \times 10^{-22}$ & $9.9 \times 10^{-22}$ & $9.7 \times 10^{-22}$ \\
\hline
\end{tabular}

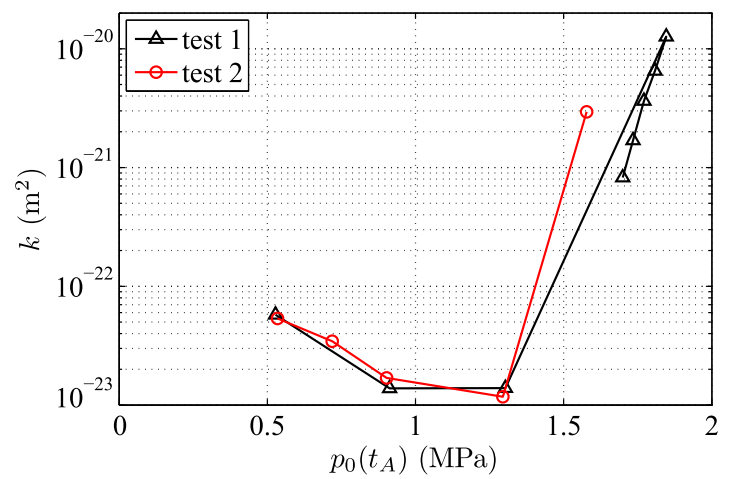

Fig. 9. Permeability measurement for the aluminium pipe.

to cracking-induced leakage. Results obtained for two tests are plotted in Fig. 9. The first local and meaningful leak occurred suddenly between 1.4 and $1.6 \mathrm{MPa}$. This quite low value ( $<2 \mathrm{MPa}$ ) can be explained by the fact that aluminium pipe stiffness is higher than the stiff composite used in Section 3.2. Indeed, manufacturing a thinner aluminium pipe with the required geometrical specifications was not practicable. Gas leak detector spray shows that the leakage is located between the sealing ring and the pipe. FE simulation made with the tested aluminium pipe agrees with experimental leakage pressure and location. Results obtained with the aluminium pipe therefore validate the design of the device. Before the first local leak, permeability is between $10^{-23} \mathrm{~m}^{2}$ and $10^{-22} \mathrm{~m}^{2}$, which is low enough to identify the effect of first cracking-induced leakages on composite permeability, as shown in Section 5.

\subsection{Uncertainty assessment}

The sealing device is assumed to prevent any leakage at the seal locations in the range of $0-20$ bars (relative pressure) for pipes of $[90 /-45 /+45 / 90]$ and $[+45 /-45]_{s}$ lay-ups. The design also ensures that no premature damage occurs at the pipe ends. Both points can be verified by applying a leak detector on the pipe and the device. The procedure for detecting leaks is presented in Section 5.2.

Permeability measurement uncertainty derives from variations in the gas volume and the estimate of the effective permeated surface, and from the pressure measurement. Assessment of these variations and their effects on the uncertainty of the permeability measurement is detailed in Appendix B. This calculation shows that permeability measurement uncertainty is mainly driven by the uncertainty of the slope $\alpha$. In fact, $\alpha$ depends directly on pressure loss, which may be very small for low permeability values (meeting the 5\% criterion for pressure loss would require more than a week of measurement for a permeability $k=10^{-23} \mathrm{~m}^{2}$ ). In this case, variations in ambient temperature may generate pressure variations of the same order of magnitude as the pressure loss. The uncertainty generated for very low permeability is between $60 \%$ and $150 \%$. For higher permeability values, uncertainty falls to $35 \%$. The uncertainty due to temperature variations may be reduced by measuring the temperature of the pipe during the test and correcting the pressure measurement by applying the ideal gas law. These uncertainty values may seem high but they remain 


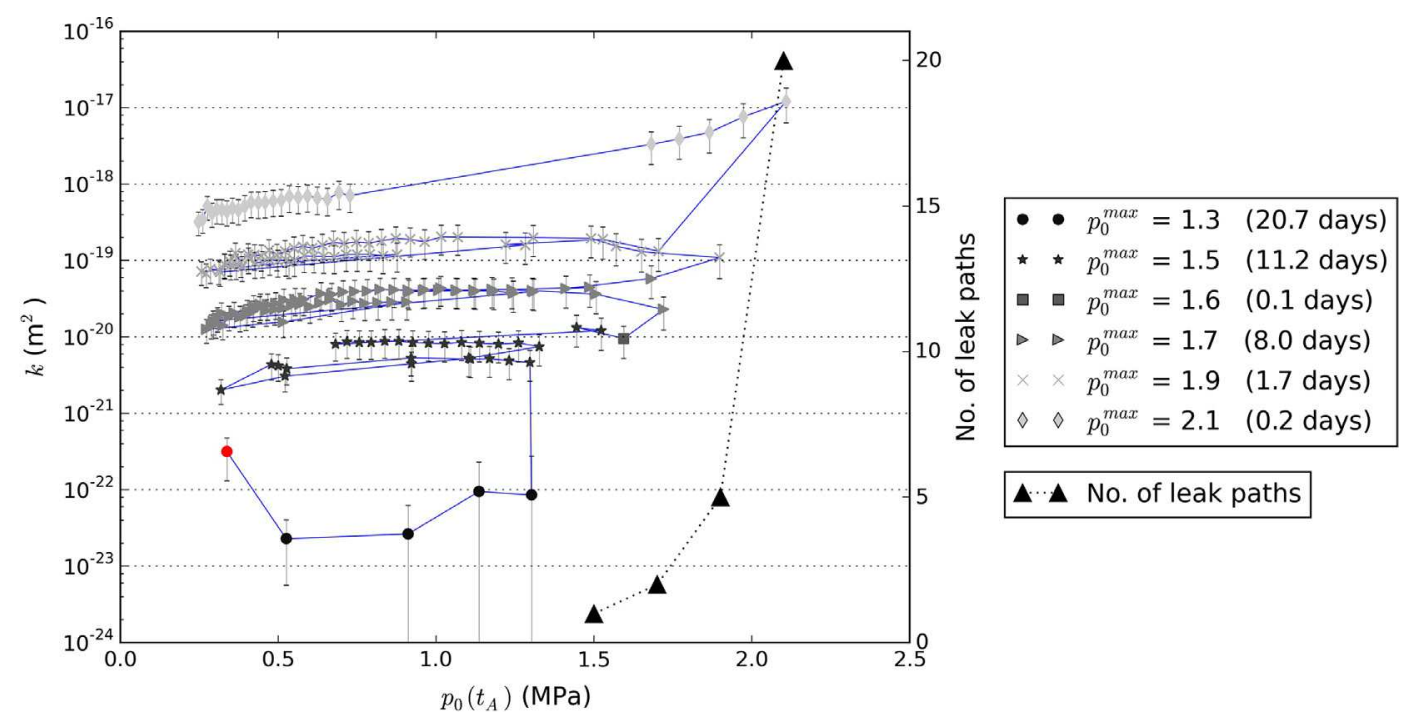

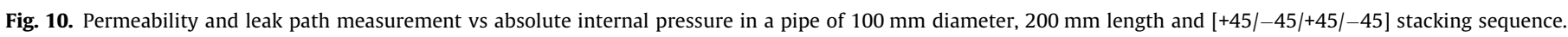

acceptable since permeability increases by several orders of magnitude when leak paths appear.

\section{Application: permeability measurement on a composite filament-wound pipe}

\subsection{Experimental settings}

The specimen we tested is a filament-wound pipe of $100 \mathrm{~mm}$ internal diameter, $200 \mathrm{~mm}$ length and thickness $e=0.8 \times 10^{-3} \mathrm{~m}$. Effective volume of gas is $V=5.6 \times 10^{-4} \mathrm{~m}^{3}$. Permeant gas is nitrogen. The material is T700 carbon fibre and epoxy matrix and the lay-up is $[+45 /-45 /+45 /-45]$. Curing is performed at a temperature of $120^{\circ} \mathrm{C}$. For this laminate sequence, the pressure load generates in-plane shear stress in the ply directions, which creates transverse cracks in mode II.

To distinguish the effect of the number of leak paths on permeability from that of their openings, it is necessary to perform pressure cycles. Each maximal applied pressure $p_{0}^{\max }$ is considered to set the damage state, and hence the number of leak paths, that is to say no leak path can be created for any pressure lower than $p_{0}^{\max }$. Thus, the pressure was set to several different maximal pressures $p_{0}^{\max }$, allowing damage to develop and leak paths to appear progressively in the pipe. At this point leak paths were localised and counted. Thereafter, the pressure was released step by step and multiple permeability measurements were run, while no crack could develop. The following maximal absolute pressures were applied: 1.5, 1.7, 1.9, $2.1 \mathrm{MPa}$.

\subsection{Results and discussion}

Both permeability measurements with uncertainty bars and number of leak paths are shown in Fig. 10. It has to be noted that complete testing of the pipe took a month and a half. Permeability values were obtained using Eq. (8), which does not take the Klinkenberg effect into account. Fig. 10 thus represents the evolution of apparent permeability. However, the effect of pressure on crack opening interacts with the effect of potential molecular flow due to diffusion in pristine material. Thus the Klinkenberg model, using a constant coefficient $b$ and the definition of an intrinsic permeability, is irrelevant for the problem studied here.

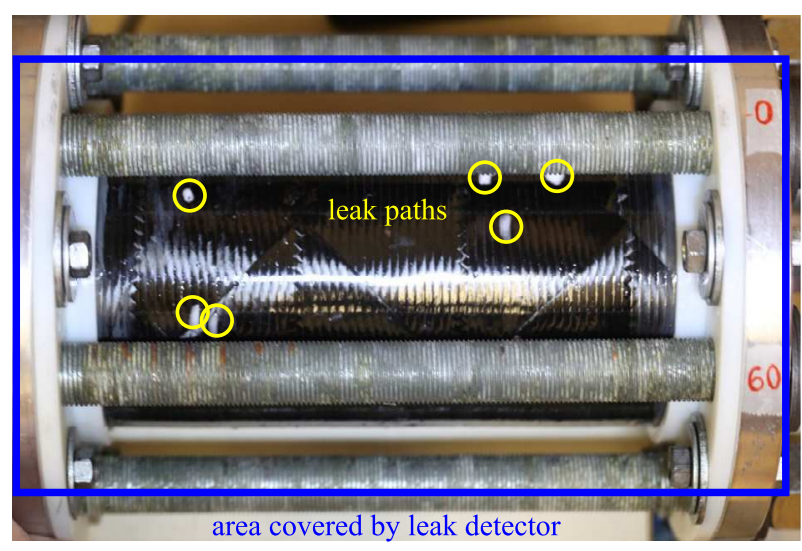

Fig. 11. Detection of leaks on the pipe and the sealing device.

Initial permeability, with the exception of the first point, is lower than $10^{-22} \mathrm{~m}^{2}$. This value is consistent with the magnitude of device leak assessed on an aluminium pipe (Fig. 9) and with the literature: Jannot and Lasseux found $k=10^{-23} \mathrm{~m}^{2}$ for a thin glass-epoxy composite plate [23]. The drop in permeability at the beginning of the test is due to a suppression of leakage of the device, as a result of pressure pushing the pipe ends onto the seals, as highlighted by FE Analysis. The first point on the graph, plotted in red, ${ }^{2}$ should be disregarded. The increase in permeability before the first leak path occurs may be due to lower scale damage, namely micro-scale spread matrix cracking and fibre matrix decohesion. Such a tiny permeability variation is tricky to measure and is not significant for the present study. As stated in Section 4.4, uncertainty is significant for low permeability values but is not detrimental when exploiting the results.

Identification of the location of leak paths is shown in Fig. 11. Several images were taken at short intervals for several minutes, and by comparing them the location of any leaks in the pipe and the sealing region could be identified. No leaks were observed at the seals or at the pipe ends.

For each new loading step, i.e. when pressure is set to a new maximal value, permeability increases by almost one order of

\footnotetext{
2 For interpretation of color in Fig. 9, the reader is referred to the web version of this article.
} 
magnitude while the number of leak paths evolves slowly, from 1 to 20 for permeability values from $4.10^{-21} \mathrm{~m}^{2}$ to $1.10^{-17} \mathrm{~m}^{2}$. When the pressure is released after damage has occurred, permeability increases slightly at first (NB: logarithmic scale flattens curves). This may be due to the viscous behaviour of the [+45/-45] stacking sequences delaying crack opening and closure. After that, cracks start to close and permeability decreases. At low pressure, the pipe does not recover its initial permeability. This correlates with a partial closure of cracks due to residual stresses of thermo-mechanical origin caused by cooling after curing at $120^{\circ} \mathrm{C}[10,30]$, and irreversible shear strains specific to [+45/-45] stacking sequences [4].

\section{Conclusion and outlook for further research}

This paper presents an experimental setup and method for assessing the load-induced permeability of a material using pipe specimens. FE analysis was performed to manage the design of the sealing components according to the radial stiffness of tested tubes. Strains and damage state at the specimen ends are then controlled and sealing of the device is ensured up to the target pressure. The device also enables leak path quantification and localisation since the external face of the tube is accessible. A robust method is applied to compute the material permeability from the progressive decrease in internal pressure. Device performances are validated on an aluminium pipe which is not subjected to crack-induced leakage. Results obtained for a composite pipe show that the device is able to highlight the relationship between the number of leak paths and the increase in material permeability in a quantitative manner. In future studies, tests will be performed on various laminate lay-ups in order to understand the role of multi-axial stress state according to ply direction in leak path creation. These results will be combined with micrography and microtomography observations to improve damage evolution laws and the effect of crack length and distribution will be added to the previous model developed by the authors [10].

\section{Acknowledgements}

The authors would like to thank the CNES, the French Space Agency, and the Regional Council of Aquitaine - France for their financial support.

\section{Appendix A. Notation}

\begin{tabular}{lll}
\hline$k$ & apparent permeability & $\mathrm{m}^{2}$ \\
$Q$ & leakage rate & $\mathrm{m}^{3} \mathrm{~s}^{-1}$ \\
$S$ & measurement area & $\mathrm{m}^{2}$ \\
$p(x, t)$ & pressure at $x$ and $t$ & $\mathrm{~Pa}$ \\
$d p / d x$ & pressure gradient along $x$ & $\mathrm{~Pa} \mathrm{~m}^{-1}$ \\
$\alpha$ & slope of the linear regression of $p_{0}(t)$ over & $\mathrm{Pa} \mathrm{m}^{-1}$ \\
& {$\left[t_{A} ; t_{B}\right]$} & \\
$p_{0}$ & upstream pressure & $\mathrm{Pa}$ \\
$p_{1}$ & downstream pressure & $\mathrm{Pa}$ \\
$\mu$ & dynamic viscosity of the fluid & $\mathrm{Pa} \mathrm{s}$ \\
$k_{m}$ & intrinsic permeability & $\mathrm{m}$ \\
$b$ & Klinkenberg coefficient & $\mathrm{Pa}$ \\
$p_{m}$ & mean of upstream and downstream & $\mathrm{Pa}$ \\
$p_{0}(t)$ & pressures & upstream pressure at time $t$ \\
$t$ & time & $\mathrm{Pa}$ \\
$x$ & coordinate along the thickness of the sample & $\mathrm{m}$
\end{tabular}

e thickness of the sample m

$L_{s} \quad$ length of the sample impacted by the device $\mathrm{mm}$

$V_{0} \quad$ upstream gas volume $\mathrm{m}^{3}$

$t_{A} \quad$ start time of the measure $\mathrm{s}$

$t_{B} \quad$ end time of the measure $\mathrm{s}$

\section{Appendix B. Uncertainty calculation}

Permeability is calculated using the following expression:

$$
\begin{aligned}
k & =\frac{2 \mu e V_{0}}{S} \frac{\alpha}{p_{0}\left(t_{A}\right)^{2}-p_{1}^{2}}=\frac{2 \mu e V_{0}}{S} \frac{\alpha}{\left(p_{0}\left(t_{A}\right)-p_{1}\right)^{2}+2\left(p_{0}-p_{1}\right) p_{1}} \\
\text { with } \alpha & =\frac{\Delta p}{\Delta t}=\frac{\tilde{p}\left(t_{B}\right)-\tilde{p}\left(t_{A}\right)}{t_{B}-t_{A}}
\end{aligned}
$$

where $A$ and $B$ denote the beginning and the end of the measurement, $\Delta p$ is the pressure loss obtained by linear regression on the time interval $\Delta t=t_{B}-t_{A}$, and $\tilde{p}(t)$ are the linearised pressures.

Relative uncertainty of $k$ according to each source of uncertainty $X_{i}$ is written:

$\frac{\delta k}{k}=\sum_{i} \frac{\partial k\left(X_{i}\right)}{\partial X_{i}} \frac{\delta X_{i}}{k}$

where variables $X_{i}$ are the dynamic viscosity $\mu$, the thickness of the pipe $e$, the effective volume of gas $V_{0}$, the effective permeated surface $S$, the slope $\alpha$ related to the pressure loss, the atmospheric pressure $p_{1}$, and the relative pressure $p_{0}(t)-p_{1} . \delta X_{i}$ is the uncertainty associated to the variable $X_{i}$. The partial derivatives of $k$ are:

$$
\begin{aligned}
& \frac{\partial k}{\partial \mu}=\frac{2 e V_{0}}{S} \frac{\alpha}{p_{0}\left(t_{A}\right)^{2}-p_{1}^{2}} \\
& \frac{\partial k}{\partial e}=\frac{2 \mu V_{0}}{S} \frac{\alpha}{p_{0}\left(t_{A}\right)^{2}-p_{1}^{2}} \\
& \frac{\partial k}{\partial V_{0}}=\frac{2 e \mu}{S} \\
& \frac{\partial k}{\partial S}=-\frac{2 e \mu V_{0}}{S^{2}} \frac{\alpha}{p_{0}\left(t_{A}\right)^{2}-p_{1}^{2}}
\end{aligned}
$$

$\frac{\partial k}{\partial\left(p_{0}\left(t_{A}\right)-p_{1}\right)}=-\frac{2 e \mu V_{0}}{S} \frac{2 \alpha p_{0}\left(t_{A}\right)}{\left[\left(p_{0}\left(t_{A}\right)-p_{1}\right)^{2}+2\left(p_{0}\left(t_{A}\right)\right)-p_{1}\right]^{2}}$

$\frac{\partial k}{\partial p_{1}}=\frac{2 e \mu V_{0}}{S} \frac{2 \alpha p_{1}}{\left[\left(p_{0}\left(t_{A}\right)-p_{1}\right)^{2}+2\left(p_{0}\left(t_{A}\right)\right)-p_{1}\right]^{2}}$

$\frac{\partial k}{\partial \alpha}=\frac{2 e \mu V_{0}}{S} \frac{1}{p_{0}\left(t_{A}\right)^{2}-p_{1}^{2}}$

Uncertainty $\delta \mu$ is computed from the effect of temperature variations on $\mu$. Uncertainty of the thickness is due to the manufacturing process of the pipe and is $\delta e / e=5 \% . \delta V_{0}$ is obtained by assessing the pressure-induced strains in the pipe and the PVC cylinder. $\delta S$ depends on the length of the pipe impacted by the sealing ring, which is between 0 and $11 \mathrm{~mm}$, as determined in Section 3.2. The maximal reasonable variation in atmospheric pressure gives $\delta p_{1}=1500 \mathrm{~Pa}$. The internal pressure $p_{0}-p_{1}$ is subject to the effect of temperature, and to the sensor drift. Uncertainty $\delta \alpha$ on the slope of the linear regression depends on the uncertainty $\delta\left(\tilde{p}\left(t_{B}\right)-\tilde{p}\left(t_{A}\right)\right)$ of pressure due to variations in temperature $T$, and $\delta\left(t_{B}-t_{A}\right)$ and is obtained by using the same uncertainty formula as Eq. (B.3): 
$\delta \alpha=\frac{\delta\left(\tilde{p}\left(t_{B}\right)-\tilde{p}\left(t_{A}\right)\right)}{t_{B}-t_{A}}-\frac{\tilde{p}\left(t_{B}\right)-\tilde{p}\left(t_{A}\right)}{\left(t_{B}-t_{A}\right)^{2}} \delta\left(t_{B}-t_{A}\right)$

As $\delta\left(t_{B}-t_{A}\right)$ is negligible compared to the duration $\left(t_{B}-t_{A}\right)$,

$\frac{\delta \alpha}{\alpha}=\frac{\delta\left(\tilde{p}\left(t_{B}\right)-\tilde{p}\left(t_{A}\right)\right)}{\tilde{p}\left(t_{B}\right)-\tilde{p}\left(t_{A}\right)}$

The uncertainty of the pressure measurement is known by applying the ideal gas law, with $n$ the amount of substance, considered constant along with the volume $V_{0}$, and $R$ the universal gas constant:

$$
\begin{aligned}
& p_{0}(t, T)=\frac{n R T}{V_{0}} \\
& \frac{\delta p_{0}(t, T)}{p_{0}(t, T)}=\frac{\delta T}{T}
\end{aligned}
$$

In the uncertainty calculations of the results, it was considered that the maximal magnitude of temperature variation was $\delta T=2 \mathrm{~K}$, and that this variation may apply to both pressures $p\left(t_{A}\right)$ and $p\left(t_{B}\right)$, which yields the following uncertainty of the pressure loss:

$\delta\left(\tilde{p}\left(t_{B}\right)-\tilde{p}\left(t_{A}\right)\right)=\frac{\delta T}{T} \tilde{p}\left(t_{A}\right)+\frac{\delta T}{T} \tilde{p}\left(t_{B}\right) \sim 2 \frac{\delta T}{T} \tilde{p}\left(t_{A}\right)$

\section{References}

[1] K. Mallick, J. Cronin, S. Arzberger, M.L. Tupper, L. Grimes-Ledesma, J. Lewis, C. Paul, J. Welsh, Ultralight Linerless Composite Tanks for In-space Applications, Jet Propulsion Laboratory, National Aeronautics and Space Administration, Pasadena, CA, 2004, URL <http://arc.aiaa.org/doi/pdf/10.2514/6.2004-5801>.

[2] K. Mallick, J. Cronin, K. Ryan, S. Arzberger, N. Munshi, C. Paul, J. Welsh, An integrated systematic approach to linerless composite tank development, in: 46th AIAA/ASME/ASCE/AHS/ASC Structures, Structural Dynamics and Materials Conference, American Institute of Aeronautics and Astronautics, Austin, Texas, 2005, URL <http://arc.aiaa.org/doi/abs/10.2514/6.2005-2089>.

[3] J.A. Nairn, S. Hu, The initiation and growth of delaminations induced by matrix microcracks in laminated composites, Int. J. Fract. 57 (1) (1992) 1-24, http:// dx.doi.org/10.1007/BF00013005.

[4] P. Ladèveze, G. Lubineau, An enhanced mesomodel for laminates based on micromechanics, Compos. Sci. Technol. 62 (4) (2002) 533-541, http://dx.doi. org/10.1016/S0266-3538(01)00145-2, URL <http://www.sciencedirect. com/science/article/pii/S0266353801001452>.

[5] D.M. Grogan, S.B. Leen, C.O.A. Semprimoschnig, C.M.Ó. Brádaigh, Damage characterisation of cryogenically cycled carbon fibre/PEEK laminates, Compos. Part A: Appl. Sci. Manuf. 66 (2014) 237-250, http://dx.doi.org/10.1016/ j.compositesa.2014.08.007, URL <http://www.sciencedirect.com/science/ article/pii/S1359835X14002401>.

[6] P. Ladevèze, G. Lubineau, Relationships between 'micro' and 'meso' mechanics of laminated composites, CR Méc. 331 (8) (2003) 537-544.

[7] J. Noh, J. Whitcomb, Prediction of delamination growth and opening near intersection of transverse matrix cracks and delamination, J. Compos. Mater. 39 (15) (2005) 1335-1352.

[8] C. Huchette, D. Lévêque, N. Carrère, A multiscale damage model for composite laminate based on numerical and experimental complementary tests, in: Proceedings of the IUTAM Symposium on Multiscale Modelling of Damage and Fracture Processes in Composite Materials, IUTAM Symposium on Multiscale Modelling of Damage and Fracture Processes in Composite Materials, Dolny, vol. 135, 2006, pp. 241-248.

[9] F. Laurin, N. Carrere, C. Huchette, J.-F. Maire, A multiscale hybrid approach for damage and final failure predictions of composite structures, J. Compos. Mater. $47(20-21)(2013) 2713-2747$.

[10] C. Bois, J.-C. Malenfant, J.-C. Wahl, M. Danis, A multiscale damage and crack opening model for the prediction of flow path in laminated composite,
Compos. Sci. Technol. 97 (2014) 81-89, URL <http://www.sciencedirect. com/science/article/pii/S0266353814001080>.

[11] A. Nair, S. Roy, Modeling of permeation and damage in graphite/epoxy laminates for cryogenic tanks in the presence of delaminations and stitch cracks, Compos. Sci. Technol. 67 (11-12) (2007) 2592-2605, http://dx.doi.org/ 10.1016/j.compscitech.2006.12.003, URL <http:// www.sciencedirect.com/science/article/pii/S0266353806004647>.

[12] D.M. Grogan, C.M.Ó. Brádaigh, S.B. Leen, A combined XFEM and cohesive zone model for composite laminate microcracking and permeability, Compos. Struct. 120 (2015) 246-261, http://dx.doi.org/10.1016/j.compstruct. 2014.09.068, URL <http://www.sciencedirect.com/science/article/pii/ S0263822314005169>.

[13] J.-C. Malenfant, Étude de l'influence de l'endommagement sur la perméabilité des matériaux composites, application à la réalisation d'un réservoir cryogénique sans liner PhD thesis, Univ. Bordeaux I, Bordeaux, France, 2012, URL <http://ori-oai.u-bordeaux1.fr/pdf/2012/MALENFANT_JEAN-CHARLES 2012.pdf $>$.

[14] P. Peddiraju, J. Noh, J. Whitcomb, D. Lagoudas, Prediction of cryogen leak rate through damaged composite laminates, J. Compos. Mater. 41 (1) (2007) 41-71.

[15] H. Kumazawa, J. Whitcomb, Numerical modeling of gas leakage through damaged composite laminates, J. Compos. Mater. 42 (16) (2008) 1619-1638.

[16] J. Xu, B.V. Sankar, S. Bapanapalli, Finite element based method to predict gas permeability in cross-ply laminates, J. Compos. Mater. 42 (9) (2008) 849-864, http://dx.doi.org/10.1177/0021998308088610.

[17] D.M. Grogan, S.B. Leen, C.M.Ó. Brádaigh, An XFEM-based methodology for fatigue delamination and permeability of composites, Compos. Struct. 107 (2014) 205-218, URL <http://www.sciencedirect.com/science/article/pii/ S0263822313003887>.

[18] S. Disdier, J. Rey, P. Pailler, A. Bunsell, Helium permeation in composite materials for cryogenic application, Cryogenics 38 (1) (1998) 135-142.

[19] H. Kumazawa, H. Hayashi, I. Susuki, T. Utsunomiya, Damage and permeability evolution in CFRP cross-ply laminates, Compos Struct 76 (1) (2006) 73-81, URL <http://www.sciencedirect.com/science/article/pii/ S0263822306002510>

[20] V. Bechel, Helium flow through cryogenically pre-conditioned composite laminates, in: Proceedings of the 50th SAMPE International Symposium, Long Beach, CA, 2005.

[21] V. Bechel, M. Negilski, J. James, Limiting the permeability of composites for cryogenic applications, Compos. Sci. Technol. 66 (13) (2006) 2284-2295.

[22] T. Yokozeki, T. Ogasawara, T. Aoki, T. Ishikawa, Experimental evaluation of gas permeability through damaged composite laminates for cryogenic tank, Compos. Sci. Technol. 69 (9) (2009) 1334-1340, URL <http://www. sciencedirect.com/science/article/pii/S026635380800211X>.

[23] Y. Jannot, D. Lasseux, A new quasi-steady method to measure gas permeability of weakly permeable porous media, Rev. Sci. Instrum. 83 (1) (2012) 015113, URL <http://scitation.aip.org/content/aip/journal/rsi/83/1/10.1063/1 3677846>.

[24] G. Rastiello, C. Boulay, S. Dal Pont, J.L. Tailhan, P. Rossi, Real-time water permeability evolution of a localized crack in concrete under loading, Cem. Concr. Res. 56 (2014) 20-28, http://dx.doi.org/10.1016/j.cemconres. 2013.09.010, URL <http://www.sciencedirect.com/science/article/pii/ S0008884613001968>

[25] T. Yokozeki, T. Aoki, T. Ishikawa, Experimental cryogenic gas leakage through damaged composite laminates for propellant tank application, J Spacecraft Rockets 42 (2) (2005) 363-366, http://dx.doi.org/10.2514/1.13955.

[26] L.J. Klinkenberg, The permeability of porous media to liquids and gases, in: Drilling and Production Practice, 1941. URL <www.onepetro.org/conferencepaper/API-41-200>.

[27] G.H. Bruce, D.W. Peaceman, H.H.J. Rachford, J.D. Rice, Calculations of unsteadystate gas flow through porous media, J. Petrol. Technol. 5 (03) (1953) 79-92, http://dx.doi.org/10.2118/221-G, URL <www.onepetro.org/journal-paper/SPE221-G>.

[28] S.E. Yamada, A.H. Jones, A review of a pulse technique for permeability measurements, Soc. Petrol. Eng. J. 20 (05) (1980) 357-358, http://dx.doi.org/ 10.2118/8760-PA, URL <www.onepetro.org/journal-paper/SPE-8760-PA>.

[29] M. Bergoglio, D. Mari, Leak rate metrology for the society and industry, Measurement 45 (10) (2012) 2434-2440, http://dx.doi.org/10.1016/j. measurement.2011.10.037, URL <http://www.sciencedirect.com/science/ article/pii/S0263224111003861>.

[30] G. Lubineau, Estimation of residual stresses in laminated composites using field measurements on a cracked sample, Compos. Sci. Technol. 68 (2008) 2761-2769, 1, http://dx.doi.org/10.1016/j.compscitech.2008.06.009. 